\title{
Erratum to STAT1-p53-p21axis-dependent stress-induced progression of chronic nephrosis in adriamycin-induced mouse model
}

\section{Editorial Office}

Annals of Translational Medicine

Correspondence to: Editorial Office. Annals of Translational Medicine. Email: editor@atmjournal.org.

Submitted Aug 04, 2021. Accepted for publication Aug 26, 2021.

doi: 10.21037/atm-2021-27

View this article at: https://dx.doi.org/10.21037/atm-2021-27

Erratum to: Ann Transl Med 2020;8:1002

After publication of the original article entitled "STAT1-p53-p21axis-dependent stress-induced progression of chronic nephrosis in adriamycin-induced mouse model" (1), it was noted that the Figure $1 B$ was incorrectly published. Corrections are needed due to carelessness on the part of the authors during the manuscript production process.

The HE staining in Figure $1 B$ were placed incorrectly, and the correct version of Figure 1 is attached as below.

The change did not affect the results or conclusion of the study.

A
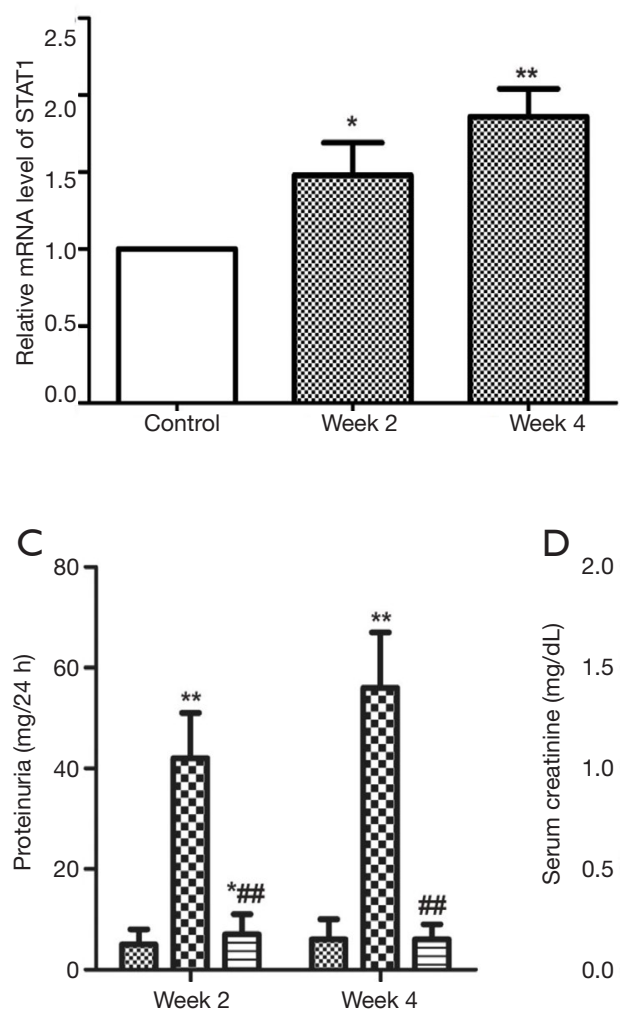

B
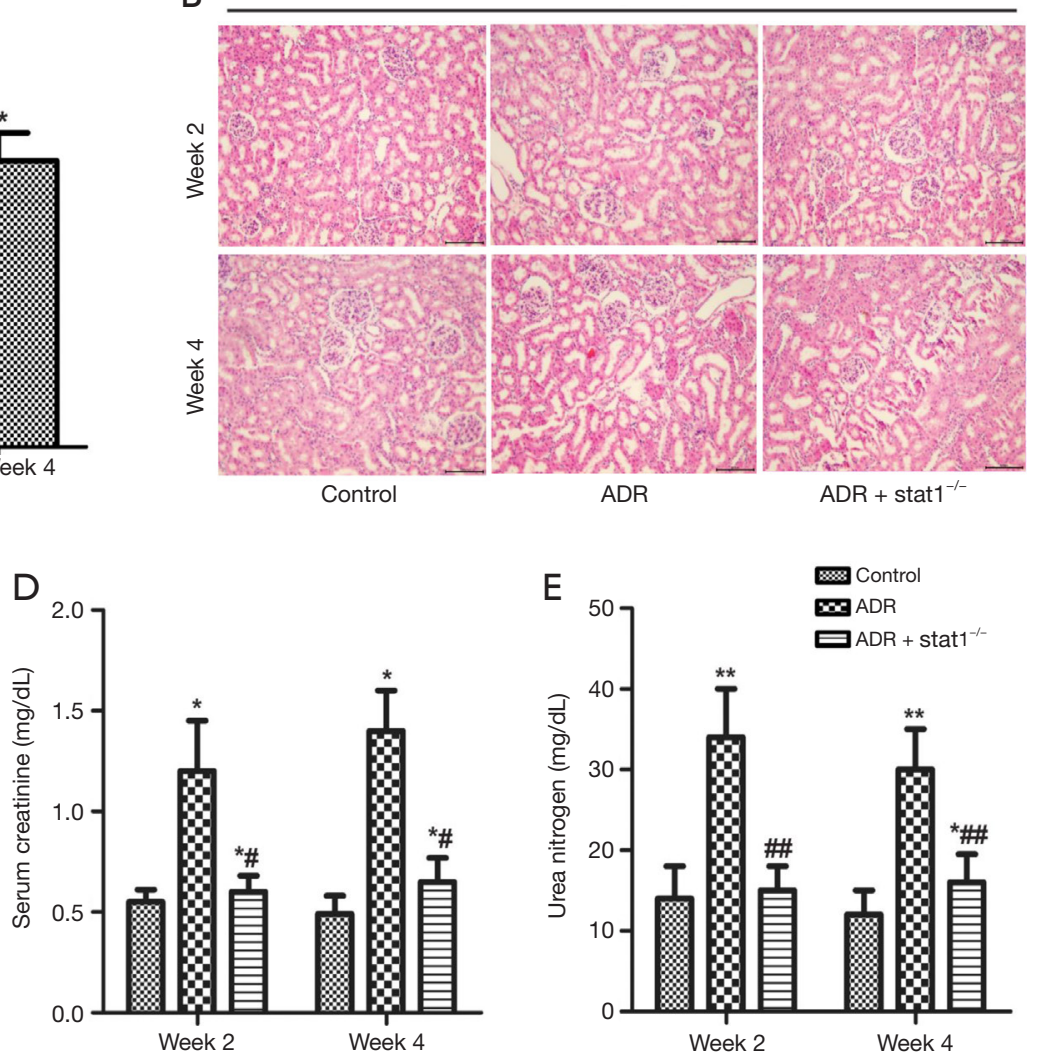

E

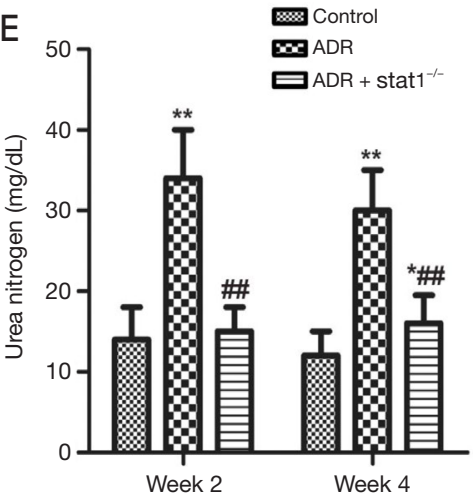


Click here to view the updated version of the article.

Open Access Statement: This is an Open Access article distributed in accordance with the Creative Commons AttributionNonCommercial-NoDerivs 4.0 International License (CC BY-NC-ND 4.0), which permits the non-commercial replication and distribution of the article with the strict proviso that no changes or edits are made and the original work is properly cited (including links to both the formal publication through the relevant DOI and the license). See: https://creativecommons.org/ licenses/by-nc-nd/4.0/.

\section{References}

1. Wei H, Wang J, Liang Z. STAT1-p53-p2 1axis-dependent stress-induced progression of chronic nephrosis in adriamycininduced mouse model. Ann Transl Med 2020;8:1002.

Cite this article as: Editorial Office. Erratum to STAT1p53-p21axis-dependent stress-induced progression of chronic nephrosis in adriamycin-induced mouse model. Ann Transl Med 2021;9(19):1512. doi: 10.21037/atm-2021-27 